\title{
Sacral Nerve Hemangiopericytoma: A Rare Case and Review of the Literature
}

\author{
Osama Ahmed ${ }^{1}$, Richard Menger ${ }^{1}$, Sunil Kukreja ${ }^{1}$, Shihao Zhang ${ }^{1}$, Christopher M. Storey ${ }^{1}$, Anil Nanda ${ }^{2}$ \& \\ Bharat Guthikonda ${ }^{3}$ \\ ${ }^{1}$ Department of Neurosurgery, Louisiana State University Health Sciences Center, Shreveport, LA, USA \\ ${ }^{2}$ Chairman, Department of Neurosurgery, Louisiana State University Health Sciences Center, Shreveport, \\ LA, USA \\ ${ }^{3}$ Department of Neurosurgery, Louisiana State University Health Sciences Center, Shreveport, LA, USA \\ Correspondence: Osama Ahmed, MD, Louisiana State University Health Sciences Center; Department of \\ Neurosurgery, 1501 Kings Highway, Shreveport, LA 71103, USA. Phone: 318-675-6404; Fax: \\ 318-675-6867. E-mail: oahmed@1suhsc.edu
}

\author{
Received: November 19, 2014 Accepted: December 11, 2014 Online Published: March 30, 2015 \\ doi:10.5539/cco.v4n1p47 \\ URL: http://dx.doi.org/10.5539/cco.v4n1p47
}

\begin{abstract}
Introduction: Hemangiopericytomas usually occur in the soft tissue and skeletal system. They rarely present in the spinal canal as a primary tumor. There are several case reports describing primary spinal hemangiopericytomas of the cervical and thoracic spine; however, there are only 3 reports of sacral hemangioperictyomas (Liu, 2013; McMaster, 1975; Zhao, 2007). We report an extremely rare presentation of a primary spinal hemangiopericytoma arising from the S2 nerve root with local bony destruction of the sacrum.

Case Report: A 52 year-old male presented with low back pain and left lower extremity numbness and tingling. MRI showed a $5.2 \mathrm{~cm} \times 5.7 \mathrm{~cm}$ sacral mass, and CT showed local bony destruction of the sacrum. He complained of left S2 pain. The patient was taken for resection of the tumor. A gross total resection was achieved from a posterior midline approach. A corridor lateral to the sacral nerves allows resection of the ventral portion of the tumor. A gross total resection was achieved with a small residual adherent to the left S2 nerve root. Pathology confirmed the tumor to be a grade II hemangiopericytoma. Adjuvant radiotherapy was recommended due to the residual.
\end{abstract}

Keywords: extramedullary; hemangiopericytoma; sacral nerve

\section{Introduction}

Hemangiopericytomas were first described by Stout and Murray in 1942 (Stout, 1942). They usually occur in the subcutaneous soft tissue and skeletal system. Rarely, hemangiopericytomas can arise from the central nervous system or bone. Osseous hemiangiopericytomas represent less than $1 \%$ of all vascular tumors while meningeal hemangiopericytomas represent $1 \%$ of all central nervous system (CNS) tumors (Dahlin, 1986). Initially considered a variant of meningiomas, hemangiopericytomas are now a separate entity deemed by the World Health Organization (WHO). Hemangiopericytomas are considered to be WHO grade II, with anaplastic hemiangiopericytomas to be WHO grade III.

There are reports of primary spinal hemiangiopericytomas, most of which are located in the cervical and thoracic spine. Rarely, they are seen in the lumbar region. To our knowledge, there are only 3 cases which report a primary spinal hemangiopericytomas arising from a sacral nerve (Liu, 2013; McMaster, 1975; Zhao, 2007). We present a rare case of a S2 hemiangiopericytoma with local destruction of the sacrum and a review of the literature.

\section{Case Reports}

A 52 year-old male presented with low back pain and left lower extremity numbness and tingling sensation for 3 months. A physical examination revealed intact motor strength in bilateral lower extremities with left S2 pain along the medial posterior aspect of the thigh. He received an MRI which showed a $5.2 \mathrm{~cm}$ x $5.7 \mathrm{~cm}$ sacral mass (Figures 1-3). 


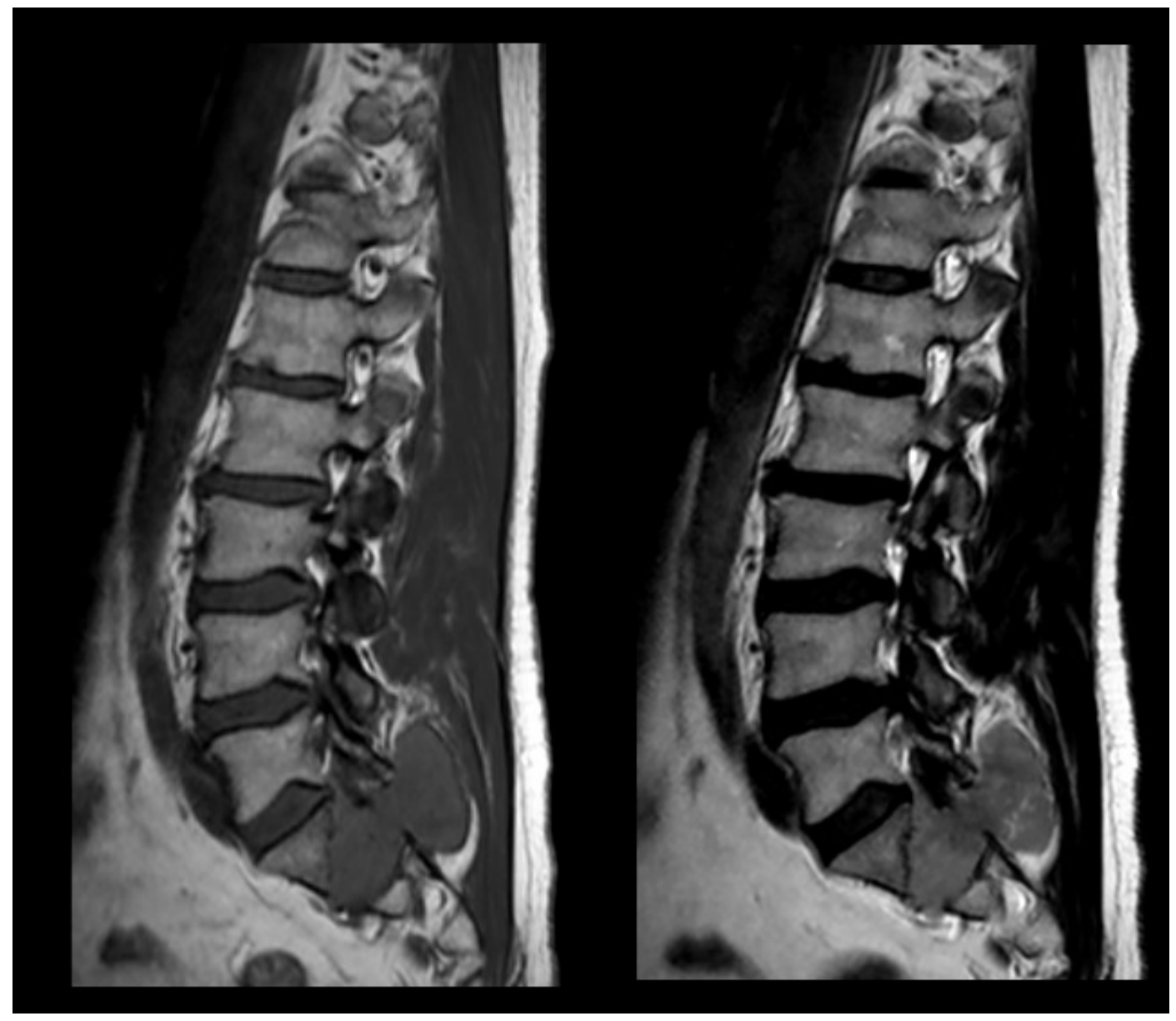

Figure 1.

Figure 2.

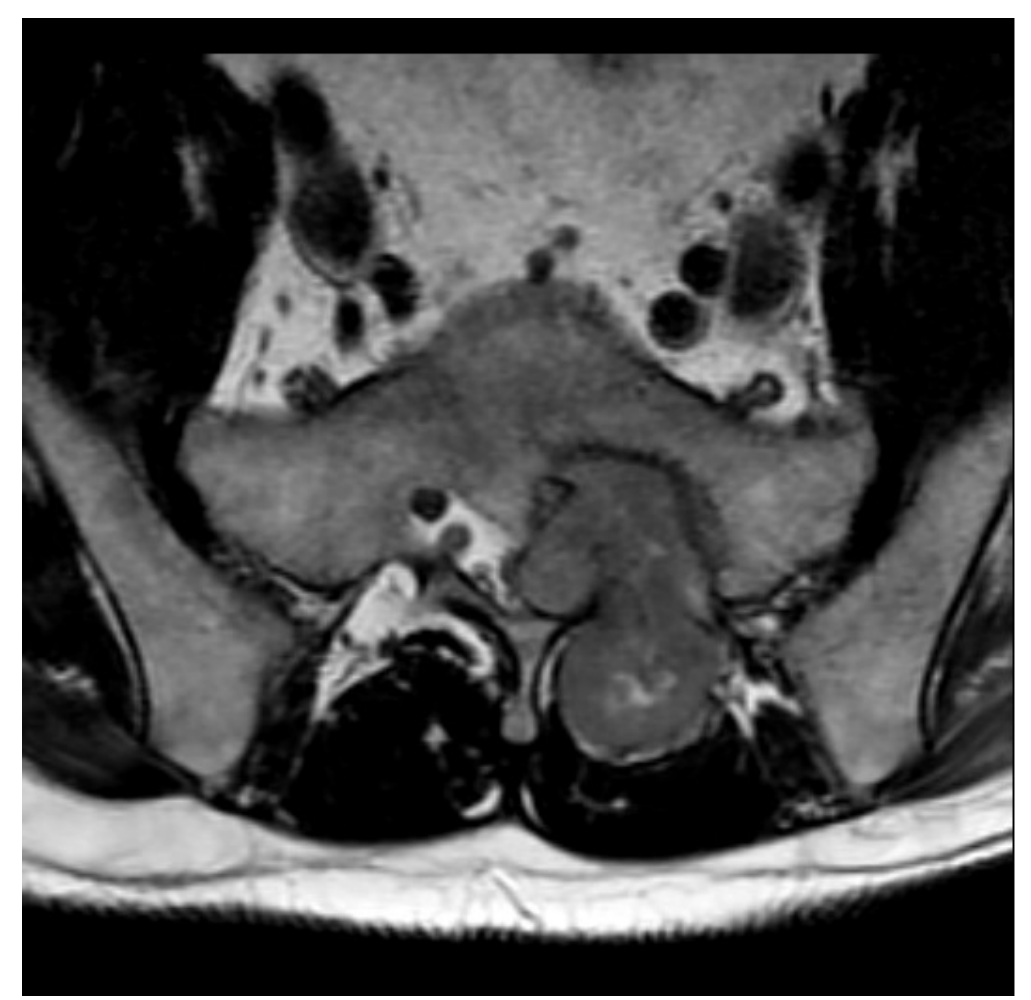

Figure 3. 
Because of anterior extension into the sacrum, a CT was obtained. The CT showed local bony destruction of the sacrum (Figure 4-5). The patient underwent a dorsal approach to an open biopsy, which revealed the mass as a hemiangiopericytoma.

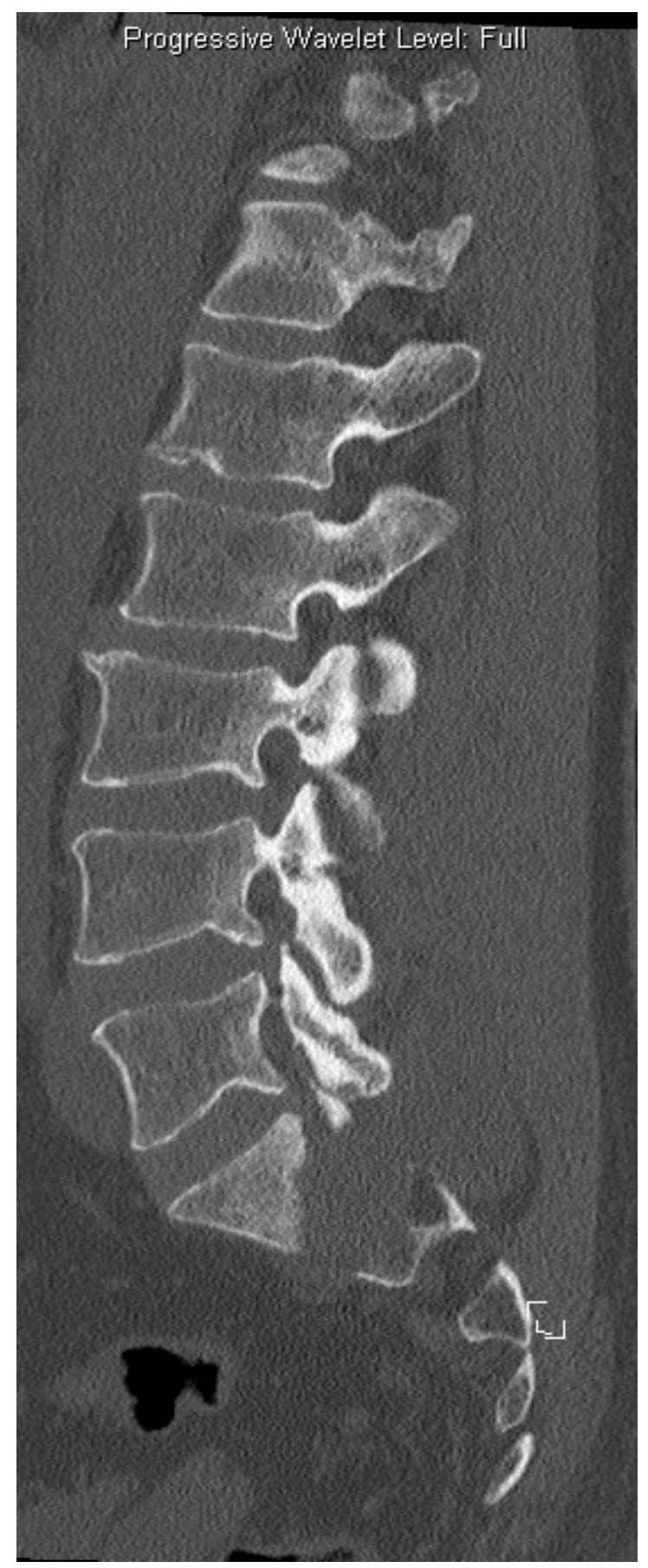

Figure 4. 


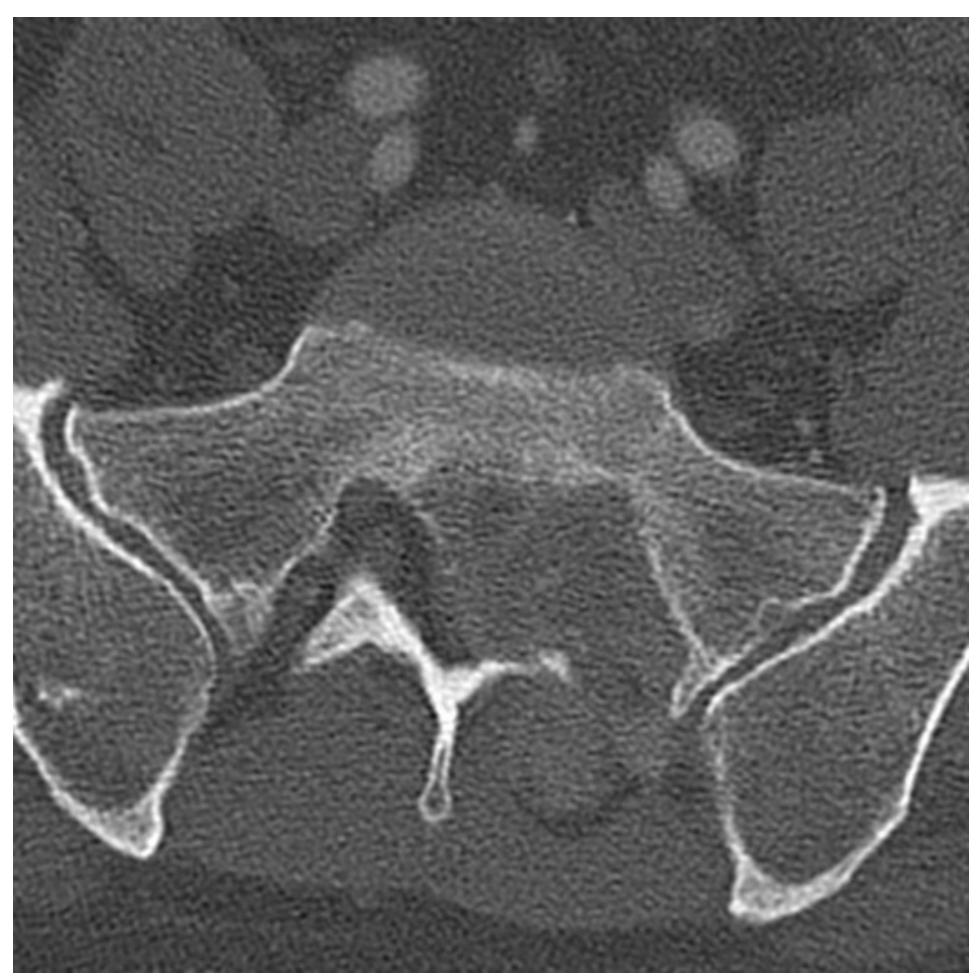

Figure 5 .

A dorsal midline approach with intraoperative monitoring was performed four weeks after the biopsy. The tumor was large, encapsulated, and lateral to the spinous process of L5. Due to its size, an en-bloc resection was not performed but resected in a piecemeal fashion. Working around the capsule, the origin of the tumor was found to be at the left S2 nerve root (Figure 6).

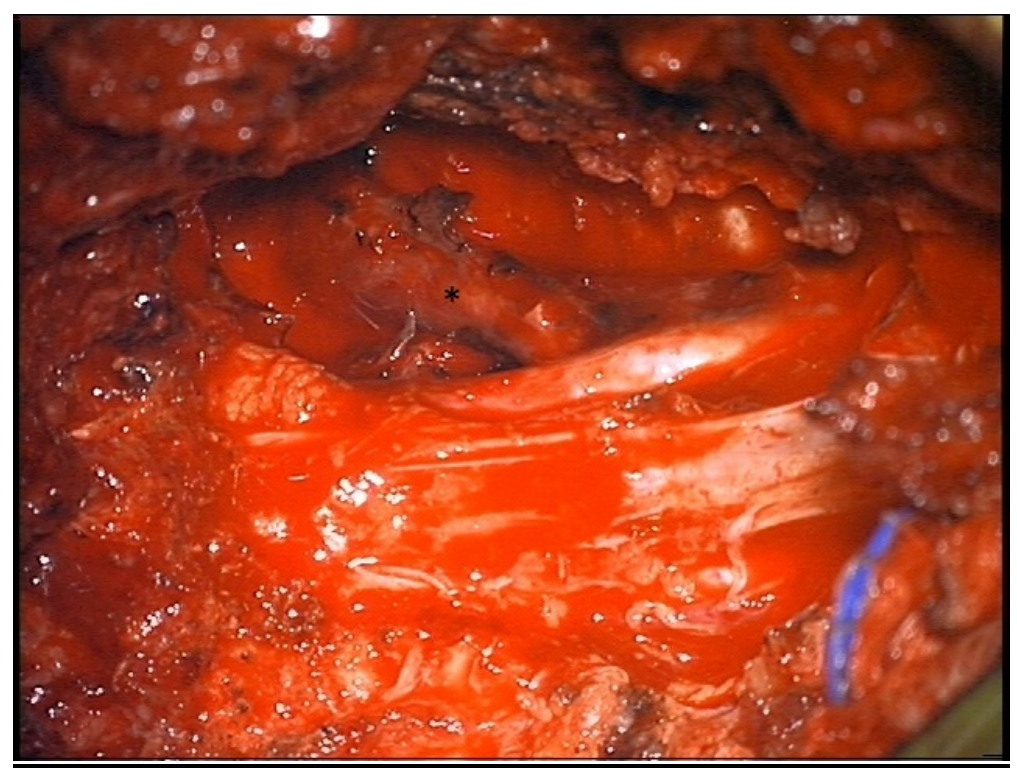

Figure 6. This is an intraoperative picture showing the origination of the tumor from the left S2 nerve root (*)

Since the patient only had sensory deficits, aggressive resection of the adherent portion of the tumor was not pursued to avoid neurological deficits. We developed a corridor to the ventral aspect of the tumor lateral to the nerve root. A sub-total resection of the tumor was achieved, which the residual portion adherent to the S2 nerve root (Figures 7-8). 


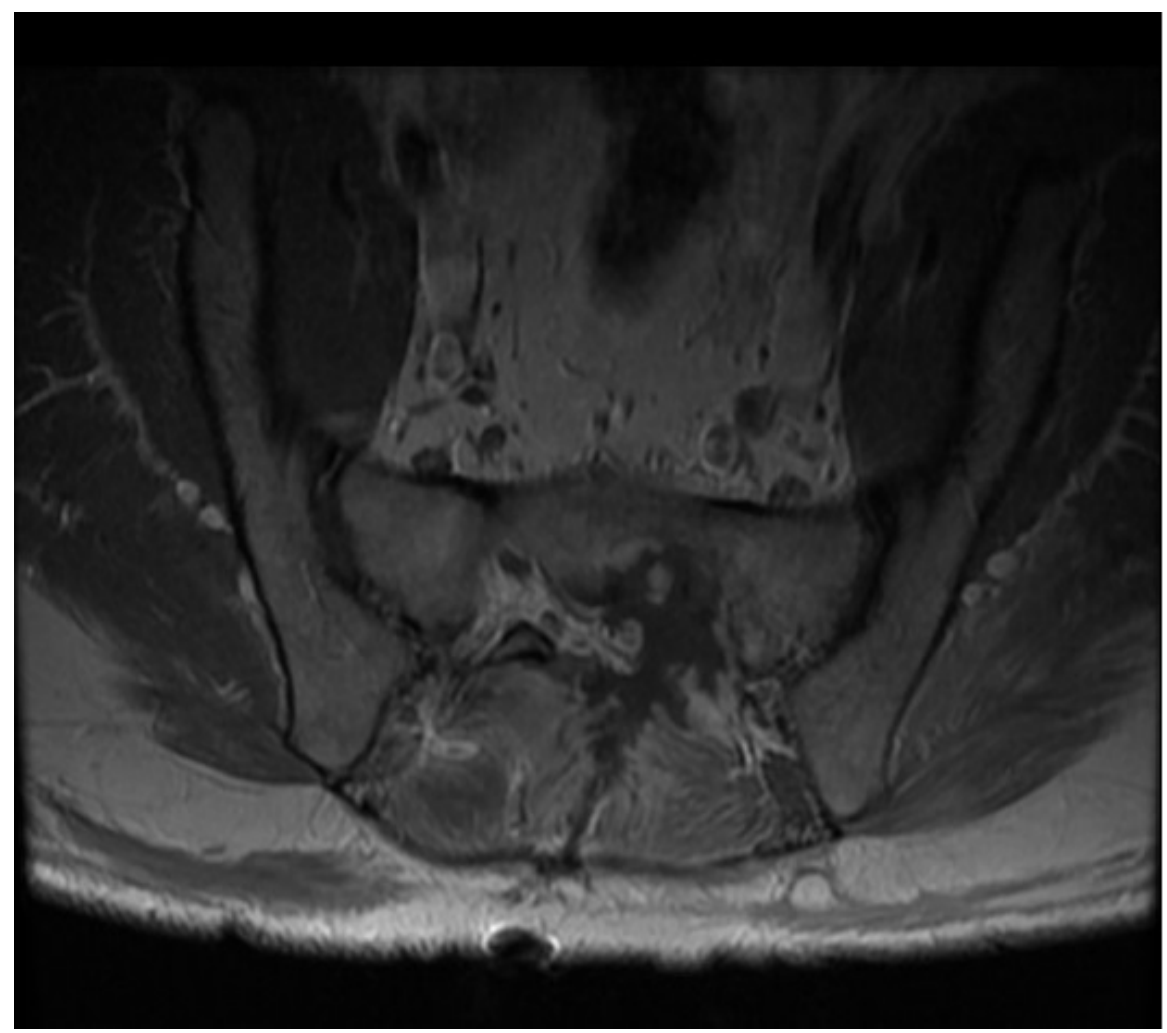

Figure 7.

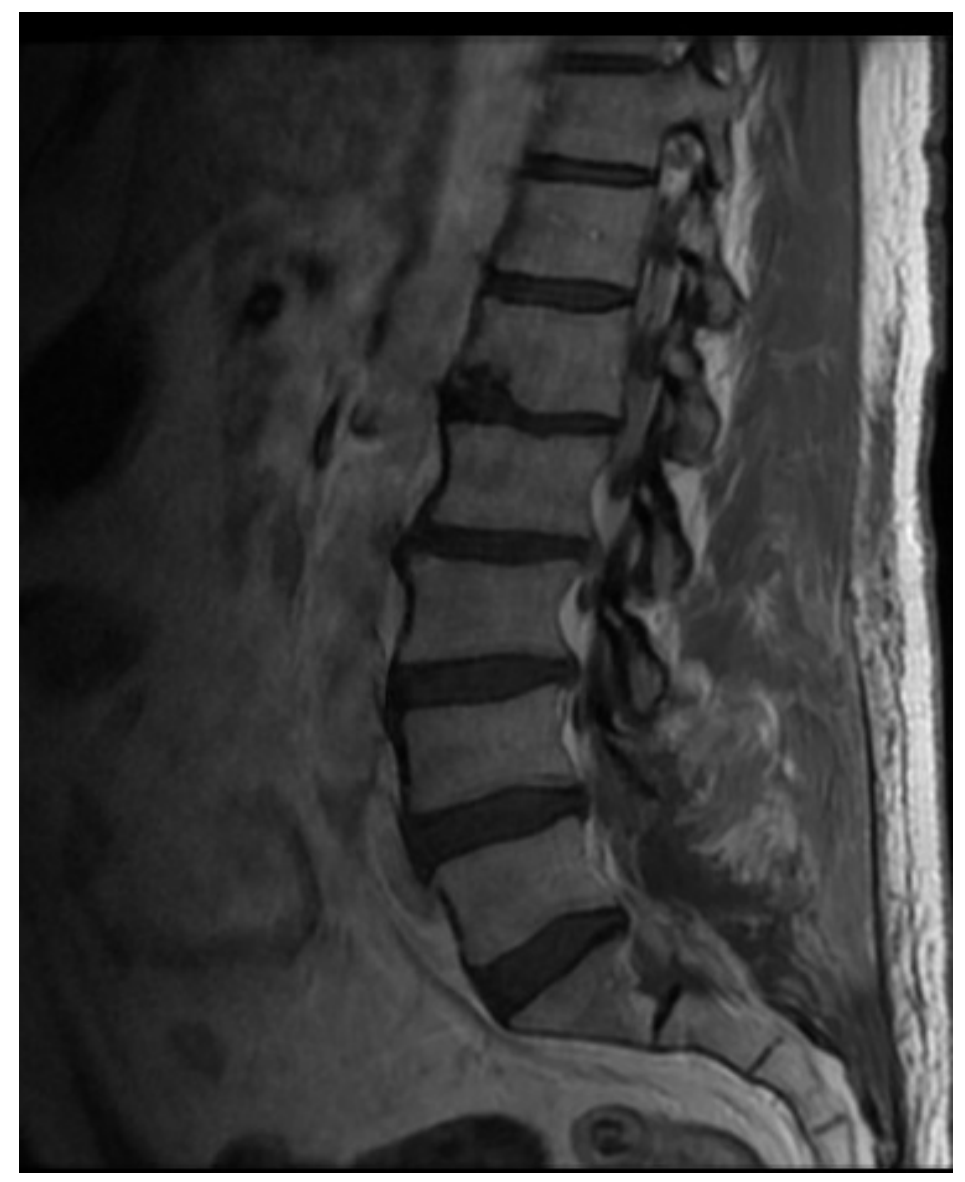

Figure 8 . 
A unilateral right-sided L4-S1 pedicle screw fusion was performed. The stability of S2 was not destroyed by the tumor, thus not requiring fixation below S1. The bony anatomy was destroyed and would not have been adequate for instrumentation due to the tumor involvement. Postoperatively, the patient was neurologically intact with resolution of his sensory deficits.

Pathology showed "staghorn" vascular channels without necrosis or hemorrhage. There was also an abundance of reticulin fibers, CD34 reactivity, and low mitotic activity, deeming this tumor to be a grade II hemangiopericytoma (Figures 9-11). Because of the residual tumor left along the nerve root, the patient received radiotherapy.

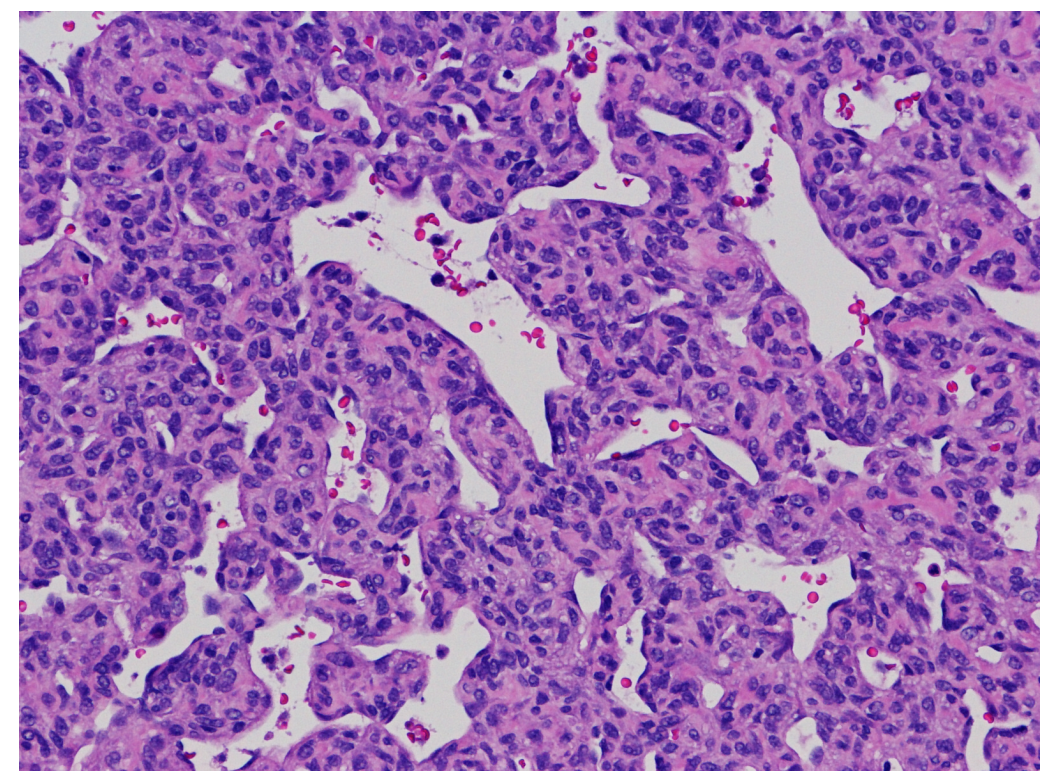

Figure 9. H\&E stain. This depicts the classic "staghorn" vascular channels associated with hemangiopericytomas. Note the then walled vessels with sinusoidal branching indicative of this pathological finding

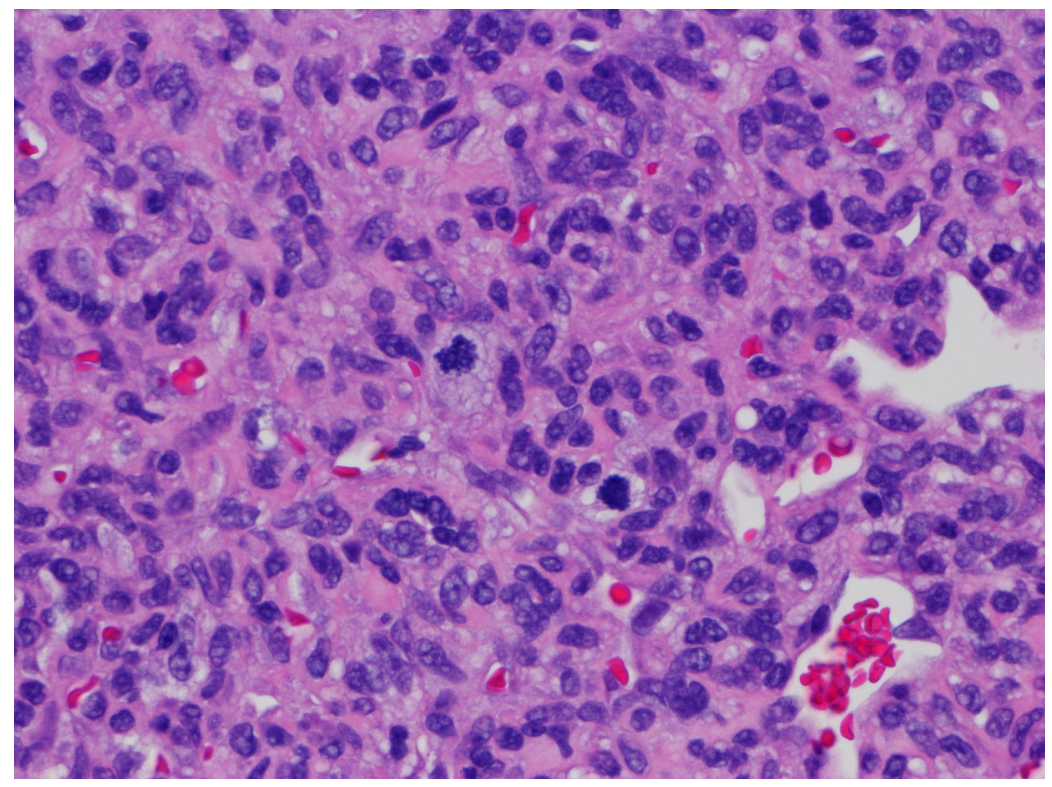

Figure 10. H\&E stain. This depicts two mitotic figures in the center of the pictures, showing low mitotic activity. This corresponds to a grade II hemangiopericytoma 


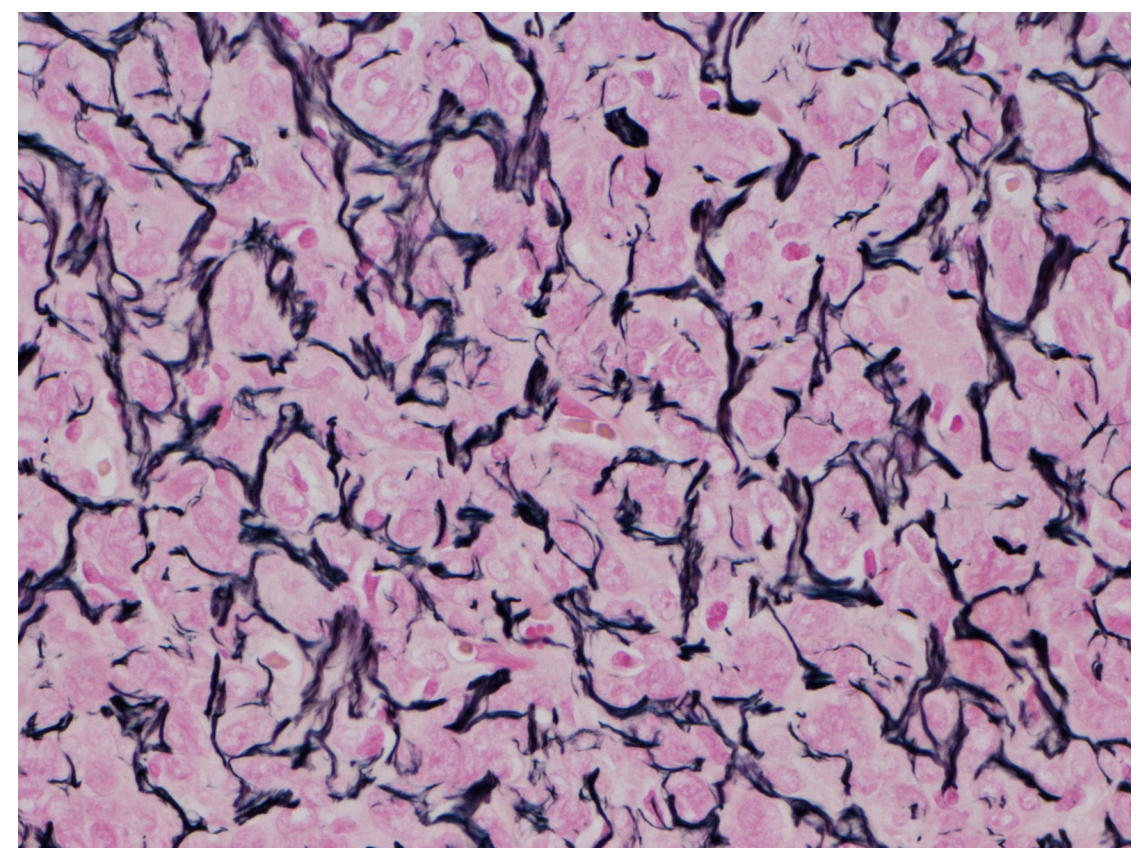

Figure 11. Silver stain. This depicts the abundant reticulin surrounding cells usually seen in hemangiopericytomas

\section{Discussion}

Hemangiopericytoma was first described Stout and Murray in 1942. They determined its origin to arise from Zimmerman's pericytes, which are pericapillary mesenchymal cells with contractile capability. Hemangiopericytomas are highly vascular, aggressive tumors that can cause local destruction of structures (Stout, 1942). These tumors usually occurs in soft tissue or skeletal system. Hemangiopericytomas usually present in the fourth and fifth decade but can range from 12 to 90 years of age. They have a male-to-female ratio of 1.8 (Tang, 1988). One percent of hemiangiopericytomas are found in the CNS (Abrahams, 1999).

The differential diagnosis is dependent on the location of its presentation. A differential diagnosis in this region includes chordoma, chondrosarcoma, giant cell tumor, schwannoma, and meningioma (Guthrie, 1989). In our case, the origin of the tumor was unclear due to the nerve root involvement and the sacral destruction. Hemangiopericytomas are categorized as a solitary fibrous tumor, which includes malignant mesothelioma, synovial cell sarcoma, leiomyomatous tumor, granulosa cell tumor, and gastrointestinal stromal tumor. In difficult cases, immunohistochemistry can aid in the diagnosis.

The radiographic characteristics of hemangiopericytomas can be nonspecific, and therefore make it difficult to diagnose preoperatively. On CT, local bony destruction can be visualized, which was present in our case. MRI T1 shows an intermediate signal tumor with contrast enhancing, serpentine, vascular channels (Mahnken, 2002; Tang, 1988).

Histologically, hemangiopericytoma cells cluster around capillaries and post-capillary venules, and contain round-to-oval nuclei. Prominent serpentine vascular channels ("staghorn") within the tumor suggest the diagnosis of hemangiopericytoma. Other tumors that can present with high-flow vascular channels include hemangioendothelioma, angiosarcoma, and sarcomas (Mahnken, 2002). Sarcomas usually have a component of necrosis and/or hemorrhage, which was not present in our case. Grade III anaplastic hemangiopericytomas contain necrosis and/or more than 5 mitosis per ten microscopics fields. Anaplastic hemangiopericytomas also contain two of the following microscopic features: hemorrhage, high cellularity, and nuclear atypia. Immunohistochemical staining of CD34 is helpful in differentiating hemiangiopericytomas from other tumors, such as primary bone tumors or metastatic carcinoma (Hulberg, 1988).

Surgery is the recommended treatment of choice for CNS hemangiopericytomas. Gross total resection can drastically improve the 5-year recurrence compared to a partial or subtotal resection (Combs, 2005). Due to their highly vascular nature, preoperative embolization can aid the surgeon in achieving gross total resection and minimizing blood loss (Fountas, 2006; Wu, 2009). We did not consider preoperative embolization as an aid for tumor resection. Fortunately, blood loss was manageable and did not prevent us from achieving a gross total 
resection.

Zweckberger et al noted the profound difficulty in these aggressive tumors based on histological grade (Zweckberger, 2011). Looking at a series of 10 cranial and 5 spinal patients, they noted radical surgical resection critical to tumor treatment. In fact, patients with grade II histology who underwent complete resection showed no recurrences or distal metastasis. However, those with grade subtotal resection grade II and those with anaplastic grade III histology require radiation therapy. Both grade II patients with subtotal resection and grade III patients showed distal metastasis (Zweckberger, 2011).

In a substantial number of cases (one-third to two-third), complete resection is not possible (Sonabed, 2014). There are reports which recorded the high rates of recurrence even if gross total resection was achieved (Guthrie, 1989). High propensity of recurrence and systemic metastasis with these lesions necessitates the use of second-line treatment options. Adjuvant radiotherapy has been shown to improve the disease-free and overall survival of the patients (Schiariti, 2011). In a recent study, Sonabend et al reported a significant improvement of overall survival with the addition of radiotherapy (Sonabend, 2014). Additionally, the role of stereotactic radiosurgery is also well established for the effective control of CNS lesions; however, there are only few cases in the literature of its usage for the spinal hemangiopericytomas (Liu, 2013).

On the contrary, there are reports that did not show any survival advantage of adjuvant radiotherapy following gross total resection $(\mathrm{p}=0.313$ ) (Ruthkowski, 2012). Gross total resection regardless of adjuvant radiotherapy does not affect the development and time to metastasis (Ruthkowski, 2012; Sonabend, 2014). Later findings incited the researchers to use chemotherapy for the better control of aggressive, recurrent and metastatic lesions. Vincristine, ifosfamide, etoposide, and doxorubicin are the most common chemotherapeutic agents used for hemangiopericytomas (Kaur, 2014). Due to their hypervascularity, some authors advocate the use of anti-angiogenesis drugs ( $\mathrm{Rh}$ endostatin and ginsenoside $\mathrm{Rg} 3)(\mathrm{Li}, 2012)$. However, the results of chemotherapy are inconsistent and is not considered to be effective adjuvant therapy (Liu, 2013). Though it is difficult to formulate a treatment guideline based on the variable reports in the literature, it appears that the upfront use of adjuvant radiotherapy to the surgical treatment improves the survival of the patients harboring these tumors (Sonabend, 2014). The synergistic role of chemotherapy especially in recurrent and malignant lesions is yet to be proven. In our case, because there was a small residual left adherent to the sacral nerve, the patient received adjuvant radiotherapy.

Schiariti et al further described hemangiopericytomas over a 24-year period follow-up. The author investigated recurrence and outcomes to various treatment modalities. Overall, the tumor was noted to be locally aggressive with distant metastases. Of their 39 patients, 5 were intraspinal and 34 were intracranial. The recurrence rate among all patients was $3.5 \%, 46 \%$, and $92 \%$ over a 1,5 , and 15 year period. Overall survival at 5 years was $93 \%$, 10 years $67 \%, 15$ years $45 \%$, and $23 \%$ at 20 years. The location of primary hemangiopericytomas had no association with overall survival. This paper defined histologic grade on the Mena classification, showing that twenty patients with low-grade histology had a statistically significant 114 months increase in overall mean survival. They also had recurrences 36 months later than their high-grade counterparts. Forty-two percent of the patients had transformation from low to high grade during their series. The most common site of metastatic presentation was the lung, bone, and liver with site of metastasis showing no relation to overall survival (Schiariti, 2011).

Shirzadi et al specifically looked at spinal hemangiopericytomas in their series to determine clinical features, surgical strategies, and outcomes. Four specific cases ages 27 to 57 were followed showing both an intramedullary and extramedullary presentation of the tumors. In review, they noted that patients with intradural hemangiopericytomas presented with less pain than patients with an extradural location. Also, interestingly in review, $100 \%$ of patients with an intramedullary tumor location survived at 3 years with a $0 \%$ metastasis rate. The most common location for hemangipericytoma was noted to be the cervical spine. They further advocated for aggressive gross total resection with the all three patients who underwent total resection surviving at three years. The patient who had a subtotal resection died. Final consensus specifically for spinal hemangiopericytomas was en-bloc resection when feasible. Unfortunately, due to the size and location of the tumor, gross total resection was achieved in a piecemeal fashion. Radiotherapy is indicated for all subtotal resections and high-grade tumors (Shirzadi, 2013).

Recurrence rates range from $44 \%$ to $88 \%$, with CNS and/or distant metastases in $14-50 \%$ of patients (Bastin, 1992; Mena, 1991; Wu, 2009). A higher grade is associated with a higher recurrence and metastasis rate (Guthrie, 1992; Mena, 1991). Because recurrence can occur years after initial treatment, long-term follow-up is warranted (Bastin, 1992; Ecker, 20013; Guthrie, 1992; Mena, 1991; Wu, 2009). Zhao et al found that the recurrence and 
metastasis rate of intradural hemangiopericytomas was $50 \%$ and $0 \%$, respectively. Of the 15 patients that had extradural tumors, he found the recurrence and metastasis rate to be $73 \%$ and $27 \%$, respectively.. The authors believed the higher recurrence rate of extradural hemangiopericytomas is due to the origin of the tumor. One of the patients in this case series had a recurrence 10 years after initial treatment, again supporting the necessity for long-term follow-up (Zweckberger, 2011). In our case, the tumor was extradural and adherent to the S2 nerve root

There are reports in the literature discussing primary spinal hemangiopericytomas, most of which are case reports. There are only 3 reports that describe a sacral hemangiopericytoma. Looking at specifically sacral presentation, a five patient case series by McMaster et al showed 1 patient presenting with a sacral hemangiopericytoma (McMaster, 1975). He described the tumor as an extradural tumor which extended through the sacral foramina into the pelvis. A subtotal resection was achieved. Another report is a 23 patient case series is by Zhao et al, of which 1 patient presented with a sacral hemangiopericytoma. It is stated that it was located in the sacral spine, but it is unknown whether the tumor originated from the nerve or whether it was an osseous hemangiopericytoma (Zhao, 2007).

Liu et al has the largest case series of primary spinal hemangiopericytomas, of which 10 were extradural. Two patients had a lumbosacral hemangiopericytoma. His male-to-female ratio was $1.17: 1$, slightly lower than what has been previously reported. The primary symptoms included pain, numbness, and paralysis. Total resection was achieved in $54 \%$ of the patients. They found no statistical difference in survival benefit in degree of resection or recurrence-free benefit, which differs from previous literature. 22 of the 26 patients received adjuvant radiotherapy, despite achieving gross total resection. The decision for adjuvant radiotherapy was based on the concern of recurrence. In our case, adjuvant radiotherapy was pursured because of the small residual adherent to the sacral nerve. In Liu's study, their 5-year survival was $76 \%$, similar to previous studies (Liu, 2013).

There are some limitations in the study and management of this patient. Because of the adherence to the S2 nerve root, en-bloc resection was not performed. In retrospect, sacrifice of the S2 nerve root with a functional contralateral S2 nerve does not lead to severe functional impairment and would have helped the authors achieve a gross total resection. Instrumentation on the side of the tumor was not feasible due to the involvement of the pedicles and ventral bony destruction. Alar or iliac screws could have aided in a bilateral construct. Certainly, long-term follow-up is needed after radiotherapy to assess for recurrence and/or metastasis.

\section{Conclusion}

Sacral spinal hemangiopericytomas are a rare entity with few reports in the literature. Preoperative diagnosis can be difficult due to its rarity and can only be diagnosed with histopathologic assessment. Due to the few number of reported cases, the best treatment option still remains unclear. Further investigation is needed to determine the best surgical and medical management.

\section{References}

Abrahams, J. M., Forman, M. S., Lavi, E., Goldberg, H., \& Flamm, E. S. (1999). Hemangiopericytoma of the third ventricle. Case report. J Neurosurg, 90(2), 359-362. http://dx.doi.org/10.3171/jns.1999.90.2.0359

Bastin, K. T., \& Mehta, M. P. (1992). Meningeal hemangiopericytoma: defining the role for radiation therapy. J Neurooncol, 1992; 14, 277-287. http://dx.doi.org/10.1007/BF00172604

Combs, S. E., Thilmann, C., Debus, J., \& Schulz-Ertner, D. (2005). Precision radiotherapy for hemangiopericytomas of the central nervous system. Cancer, 104(11), 2457-2465. http://dx.doi.org/10.1002/cncr.21448

Dahlin, D. C., \& Unni, K. K. (1986). Hemangioendothelioma (hemangiosarcoma) and hemangiopericytoma. In Dahlin (Ed.), Bone tumors. General aspects and data on 8452 cases (pp. 394-405). Illinoid: Thomas.

Ecker, R. D., Marsh, W. R., Pollock, B. E., Kurtkaya-Yapicier, O., McClelland, R., Scheithauer, B. W., et al. Hemangiopericytoma in the central nervous system: treatment, pathological features, and long-term follow up in 38 patients. J Neurosurg, 98(6), 1182-1187. http://dx.doi.org/10.3171/jns.2003.98.6.1182

Espat, N. J., Lewis, J. J., Leung, D., Woodruff, J. M., Antonescu, C. R., Shia, J., et al. (2002). Conventional hemangiopericytoma. Modern analysis of outcome. Cancer, 95, 1746-1751. http://dx.doi.org/10.1002/cncr.10867

Fountas, K. N., Kapsalaki, E., Kassam, M., Feltes, C. H., Dimopoulos, V. G., Robinson, J. S., et al. (2006). Management of intracranial meningeal hemangiopericytomas: outcomes and experience. Neurosurg Rev, 
29(2), 145-53. http://dx.doi.org/10.1007/s10143-005-0001-9

Gerner, R. E., Moore, R. E., \& Pickren, J. W. (1974). Hemangiopericytoma. An analysis of 106 cases. Ann Surg, $179(2), 128-132$.

Guthrie, B. L., Ebersold, M. J., Scheithauer, B. W., \& Shaw, E. G. (1989). Meningeal hemangiopericytoma: histopathological features, treatment, and long-term follow-up of 44 cases. Neurosurgery, 25(4), 514-522. http://dx.doi.org/10.1227/00006123-198910000-00003

Hayashi, Y., Uchiyama, N., Hayashi, Y., Nakada, M., Iwato, M., Kita, D., et al. (2009). A reevaluation of the primary diagnosis of hemangiopericytoma and the clinical importance of differential diagnosis from solitary fibrous tumor of the central nervous system. Clin Neurol Neurosurg, 111(1), 34-38. http://dx.doi.org/10.1016/j.clineuro.2008.07.010

Hulberg, B. M., Daugaard, S., Johansen, H. F., Mouridsen, H. T., Hou-Jensen, K. (1988). Malignant haemangiopericytomas and haemangioendotheliosarcomas: an immunohistochemical study. Histopathology, 12(4), 405-414. http://dx.doi.org/10.1111/j.1365-2559.1988.tb01955.x

Jaaskelainen, J., Servo, A., Haltia, M., Wahlström, T., \& Valtonen, S. (1985). Intracranial hemangiopericytoma: radiology, surgery, radiotherapy, and outcome in 21 patients. Surg Neurol, 23(3), 227-36. http://dx.doi.org/10.1016/0090-3019(85)90087-4

Kaur, J., Pandit, S., Sharma, M. C., Julka, P. K., Rath, G. K. (2014). Intradural extra medullary hemangiopericytoma of dorsal spine. Childs Nerv Syst, 2014. http://dx.doi.org/10.1007/s00381-014-2505-5

Kim, J. H., Jung, H. W., Kim, Y. S., Kim, C. J., Hwang, S. K., Paek, S. H., et al. (2003). Meningeal hemiangiopericytomas: long-term outcome and biological behavior. Surg Neurol, 59(1), 47-53. http://dx.doi.org/10.1016/S0090-3019(02)00917-5

Li, X. D., Jiang, J. T., \& Wu, C. P. (2012). Combined Therapy against Recurrent Hemangiopericytoma: A Case Report. Cancer Biol Med, 9, 141-143.

Liu, H. G., Yang, A. C., Chen, N., Yang, J., Qiu, X. G., \& Zhang, J. G. (2013). Hemangiopericytomas in the Spine: Clinical Features, Classification, Treatment, and Long-term Follow-up in 26 Patients. Neurosurgery, 72(1), 16-24. http://dx.doi.org/10.1227/NEU.0b013e3182752f50

Mahnken, A. H. (2002). Cross-section imaging of primary osseous hemangiopericytoma. Eur Radiol, 12, 85-89. http://dx.doi.org/10.1007/s003300101027

McMaster, M. J., Soule, E. H., \& Ivins, J. C. (1975). Hemangiopericytoma. A clinicopathologic study and long-term follow-up of 60 patients. Cancer, 36(6), 2232-2244. http://dx.doi.org/10.1002/cncr.2820360942

Mena, H., Ribas, J. L., Pezeshkpour, G. H., Cowan, D. N., \& Parisi, J. E. (1991). Hemangiopericytoma of the central nervous system: a review of 94 cases. Hum Pathol, 22(1), 84-91. http://dx.doi.org/10.1016/0046-8177(91)90067-Y

Rutkowski, M. J., Jian, B. J., Bloch, O., Chen, C., Sughrue, M. E., Tihan, T., et al. (2012). Intracranial hemangiopericytoma: clinical experience and treatment considerations in a modern series of 40 adult patients. Cancer, 118, 1628-1636. http://dx.doi.org/10.1002/cncr.26411

Shirzadi, A., Drazin, D., Gates, M., Shirzadi, N., Bannykh, S., Fan, X., et al. (2013). Surgical management of primary spinal hemangiopericytomas: An institutional case series and review of the literature. Eur Spine J, 22(Suppl 3), S450-59. http://dx.doi.org/10.1007/s00586-012-2626-z

Schiariti, M., Goetz, P., El-Maghraby, H., Tailor, J., \& Kitchen, N. (2011). Hemangiopericytoma: long-term outcome revisited. J Neurosurg, 114, 747-755. http://dx.doi.org/10.3171/2010.6.JNS091660

Sonabend, A. M., Zacharia, B. E., Goldstein, H., Bruce, S. S., Hershman, D., Neugut, A. I., et al. (2013). The role for adjuvant radiotherapy in the treatment of hemangiopericytoma: a Surveillance, Epidemiology, and End Results analysis. J Neurosurg, 120, 300-308. http://dx.doi.org/10.3171/2013.10.JNS13113

Stout, A. P., \& Murray, M. R. (1942). Hemangiopericytoma: a vascular tumor featuring Zimmerman's pericytes. Ann Surg, 116, 26-33. http://dx.doi.org/10.1097/00000658-194207000-00004

Tang, J. S. H., Gold, R. H., Mirra, J. M., \& Eckardt, J. (1988). Hemangiopericytoma of bone. Cancer, 62, 848-859. http://dx.doi.org/10.1002/1097-0142(19880815)62:4<848::AID-CNCR2820620434>3.0.CO;2-5

Wu, W., Shi, J. X., Cheng, H. L., Wang, H. D., Hang, C. H., Shi, Q. L., et al. (2009). Hemangiopericytomas in the central nervous system. J Clin Neurosci, 16(4), 519-523. http://dx.doi.org/10.1016/j.jocn.2008.06.011 
Zhao, Y., \& Zhao, J. Z. (2007). Clinical and pathological characteristics of primary intraspinal hemangiopericytoma and choice of treatment. Chin Med J (Engl), 120(2), 115-119.

Zweckberger, K., Jung, C. S., Muellar, W., Unterberg, U., \& Schick, U. (2011). Hemangiopericoytomas grade II are not benign tumors. Acta Neurochirgurgica, 153(2), 385-394. http://dx.doi.org/10.1007/s00701-010-0877-1

\section{Copyrights}

Copyright for this article is retained by the author(s), with first publication rights granted to the journal.

This is an open-access article distributed under the terms and conditions of the Creative Commons Attribution license (http://creativecommons.org/licenses/by/3.0/). 